\title{
Neural network-PID controller for roll fin stabilizer
}

\author{
Hassan Ghassemi, Associate Prof. \\ Fatemeh Hoseini Dadmarzi, MSc Graduated \\ Parviz Ghadimi, Assistant Prof. \\ Faculty of Marine Technology, Amirkabir University of Technology, Tehran, Iran \\ Babak Ommani, MSc Graduated \\ Faculty of Mechanical Engineering, Sharif University of Technology, Tehran, Iran
}

\begin{abstract}
Fin stabilizers are very effective devices for controlling the ship roll motion against external wave-generated moments. Lift forces due to flow around fin with an angle of attack produce anti-roll moment. Therefore control of attack angle plays important role in reducing roll of ships. This paper presents results of using a combined neural network and PID for roll control of ship with small draught. Numerical results are given of around-fin flow analysis with considering free surface effect modelled by neural network and imposed to controlling loop. Hydraulic machinery constraints are also considered in the modelling. The obtained results show good performance of the controller in reducing roll amplitude in random seas. The approach can be used for any irregular sea conditions.
\end{abstract}

Key words: Fin stabilizer; neural network; PID control; restoring force

\section{INTRODUCTION}

The aim of using roll stabilizing systems on ships depends on requirements of their mission such as the preventing against damage of cargo, increasing the effectiveness of crew or accuracy of positioning and handling weapons on naval vessels.

Roll motion is one of the most important ship motions. A large number of papers and publications are available on modelling the ship roll motion. There are many ship mission parameters influenced by rolling, such as safety of cargo, crew and passengers, fuel combustion, weapon positioning etc. Most of the roll stabilizers create a moment against roll exciting moment to decrease roll angle amplitude.

Fin stabilizer systems are found useful for roll damping. In this case, simulation of flow field around the fin and its performance has important role in research on decreasing the roll angle.

Lifting characteristics of the fins have been reasonably well predicted by semi-empirical formulae by Whicker and Fehlner [1] and Pitt et al. [2]. Sheldahl et al. [3] presented also experimental data of NACA0015 foil obtained in a wind tunnel test.

Hydrofoil lift characteristics are among thoroughly studied subjects and many papers and text books have been published in this regards (Newman. [4]).

Numerical results of foil analysis including cavitation and 2D and 3D free surface effects were published by Bal et al. [5]. They. presented also an improved numerical wave tank model for the hydrofoils by considering cavitations.
Effects of free surface and wave generated by a strut on fins attached to it were also studied numerically and experimentally by Lee et al. [6].

In this paper the results of flow field analysis around fin stabilizer including free surface, presented by the authors [7], are used for modelling the fin in the controlling loop. According to the results, hydrofoil lift characteristics are influenced by the presence of free surface in case of a considered small naval vessel.

There are many nonlinear and free-surface effects involved in modelling behaviour of fin stabilizer. The effects have been discussed in detail e.g. by Tristan Perez [8]. In dynamic modelling for controller design it is useful to include as much nonlinear and environmental effects as possible in order to achieve more accurate model without losing controllability of the system.

There are many controlling methods which could be used to achieve a good performance of fin stabilizers, for instance: PID, fuzzy logic, neural network. There are many papers on using traditional PID controller in fin stabilizers. The work by S. Surendrana et al. [9] can be referred to as an example of using PID in controlling the fin stabilizer. They used the CFD for calculating fin hydrodynamic behaviour by solving flow around a 3D horizontal fin attached to a wall.

In order to improve the performance of PID controller in fin stabilizing a combination of PID and modern controlling methods is sometimes used. For instance, the using of fuzzyPID controller has been presented by Liang et al. [10].

In the present work the results of using NN-PID controllers in series arrangement are presented. The combined controller 
in parallel arrangement was used for trajectory tracking of robotic manipulators by Wu et al. [11]. The performance of NN controlling algorithm was tested in four degrees-of-freedom by Zirilli et al. [12]. Moreover, Alarcin et al. [13] used neural network to control a rudder roll stabilizer.

In the present work the controlling loop consists of: ship dynamic model, neural network model of fin hydrodynamics, PID controller and inverse neural network model of ship heeling moment. In order to increase accuracy of the results, constraints of a hydraulic mechanism used for turning fins are also added to the fin model. According to the results presented by the authors [7] lifting force of fins with two opposite and equal attack angles, placed on two sides of sample ship should not be equal. In order to obtain a desirable restoring moment at large roll angles, two different angles of attack should be used instead of equal and opposite angles. Therefore in the present work, instead of using two equal angles with opposite signs for fins, equal portions of restoring moment from each fin is considered a desired situation. Neural network models are trained by using classical Error Back Propagation (EBP) technique. Combined NN-PID controllers are designed and optimized by using the MATLAB and Simulink environment. This combination shows good results in reducing ship roll motion resulting from external disturbances. It is worth to mention that instead of modelling the waves, exciting force is modelled as a disturbance in controlling loop.

\section{GOVERNING EQUATION}

There are many approaches to developing the ship roll governing equation, such as linear, nonlinear, coupled and uncoupled methods. In this paper the model presented by T. Perez [8] is used to derive a model for controlling loop design. The uncoupled ship roll motion equation is as follows:

$$
\mathrm{I}_{\phi \phi} \ddot{\phi}+\mathrm{B} \dot{\phi}+\mathrm{C} \phi=\tau_{\text {control }}+\tau_{\text {exiting }}
$$

In Eq. (1), $\tau_{\text {control }}$ is the restoring moment produced by fins, and $\tau_{\text {exiting }}$ is the roll exciting moment applied to the ship.

There are analytical equations for calculating the lift force of fins in function of angle of attack, but in the present work numerical results accounting for the free surface effects, were used.

It is important to note that the effective attack angle of fins may change because of roll motion and a new attack angle should be considered in finding the restoring moment. The formula for calculating the effective attack angle is given by Eq. (2) and (3):

$$
\begin{gathered}
\alpha_{\mathrm{fl}}=\arctan \left(\frac{\mathrm{r}_{\mathrm{f}} \dot{\phi}}{\mathrm{U}}\right) \approx \frac{\mathrm{r}_{\mathrm{f}} \dot{\phi}}{\mathrm{U}} \\
\alpha_{\text {effective }}=\alpha_{\mathrm{fl}}+\alpha
\end{gathered}
$$

The force component which is directed perpendicularly to the flow velocity far ahead the foil constitutes the lifting force represented by the lift coefficient. Eq. (4) shows the relation between the restoring moment and lift coefficient used for calculating the moment:

$$
\mathrm{M}_{\text {restoring }}=1 / 2 \rho \mathrm{AU}^{2} \mathrm{C}_{\mathrm{L}} \mathrm{r}_{\mathrm{f}}
$$

\section{MODELING}

The first step of controller design is modelling. There are two different elements which should be modelled in this problem: vessel and fin stabilizer.

\section{Vessel modeling}

In this work a naval vessel model prepared by Blanke and Christensen [14] is used. The model was also implemented by Perez [8] and MARINTEK at NTNU through open source MATLAB tool box, called MSS. The model contains all coefficients for nonlinear ship manoeuvring in surge, sway, yaw and roll. Tab. 1 shows the ship's main dimensions and properties.

Tab. 1. Main particulars of the ship

\begin{tabular}{|c|c|}
\hline $\mathrm{L}$ & $51.5 \mathrm{~m}$ \\
\hline $\mathrm{B}$ & $8.6 \mathrm{~m}$ \\
\hline $\mathrm{D}$ & $2.3 \mathrm{~m}$ \\
\hline$\Delta$ & $362000 \mathrm{Kg}$ \\
\hline $\mathrm{I}_{\mathrm{zz}}$ & $47934^{*} 10^{\wedge} 6$ \\
\hline $\mathrm{I}_{\mathrm{xx}}$ & $2376 *^{*} 10^{\wedge} 6$ \\
\hline $\mathrm{U}$ & $8 \mathrm{~m} / \mathrm{s}$ \\
\hline $\mathrm{KM}$ & $4.47 \mathrm{~m}$ \\
\hline $\mathrm{KB}$ & $1.53 \mathrm{~m}$ \\
\hline $\mathrm{GM}$ & $1.1 \mathrm{~m}$ \\
\hline $\mathrm{LCG}$ & $20.41 \mathrm{~m}$ \\
\hline $\mathrm{VCG}$ & $3.36 \mathrm{~m}$ \\
\hline
\end{tabular}

The model was modified in order to be combined with fin-stabilizer. The initial values are: surge, sway, roll and yaw velocities as well as roll and yaw angles. The inputs are: surge and sway forces as well as roll and yaw moments. For purpose of our task the sway and yaw moment is set to be zero and the surge force to be constant in order to simulate behaviour of the ship on straight course with the constant speed of about $8 \mathrm{~m} / \mathrm{s}$.

The roll moment is summation of the fin-stabilizing moment and an exciting moment due to environmental effects. The exciting roll moment is simply modelled by combining the sinusoidal moments with different amplitudes, frequencies and phase angles. It should be noted that it was not an intention of the authors of this work to calculate a real exciting roll moment in waves.

The model outputs are: surge, sway roll and yaw velocities as well as roll and yaw angles. Although the straight course at constant forward speed were only used for the simulation, the model is capable of being applied to simulating roll in turning or other manoeuvring scenarios.

\section{Fin-stabilizer modeling}

In the present work the fin-stabilizer consisted of two identical non-rectangular hydrofoils of a low aspect ratio, symmetrically placed on both sides of vessel. The geometrical properties of fins are specified in Tab. 2, and Fig. 1 shows schematically the shape of the fin.

Tab. 2. Fin parameters

\begin{tabular}{|c|c|}
\hline Foil section & NACA0015 \\
\hline Tip chord $[\mathrm{m}]$ & 0.9 \\
\hline Root chord $[\mathrm{m}]$ & 1.8 \\
\hline Span $[\mathrm{m}]$ & 1 \\
\hline Area $\left[\mathrm{m}^{2}\right]$ & 2.25 \\
\hline
\end{tabular}

Hydrodynamic effects of the fin on vessel's behaviour are considered negligible. In other words it is assumed that, except of roll controlling moment, the fin does not have any other effect on vessel's manoeuvring model. Because of the small draught of the vessel, the free surface effects on hydrodynamic fin coefficient, 
are important. Only the calm free surface effects are considered in modelling the fins hydrodynamic properties. Effects of waves could be later added to controlling loop as a disturbing noise.

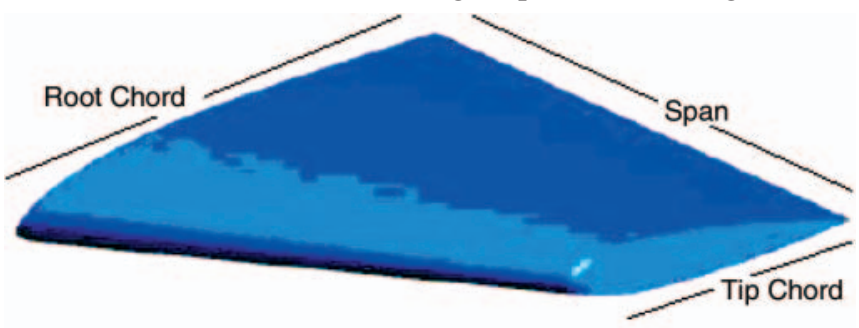

Fig. 1. Schematic shape of the fin

These authors investigated the flat free surface effects on hydrofoil's lift coefficients by using the CFD and RANS model presented elsewhere, [7]. A sample case of free surface shape around ship and fin is presented in Fig. 2. The results of hydrodynamic lift coefficient in function of attack angle of fin and roll angle of ship are presented in Fig. 3. For considering the fin's hydrodynamics in control loop, a simple neural network model is trained to follow this diagram. The trained neural network model inputs are: fin's attack angle and ship's roll angle, and the output is fin lift coefficient.

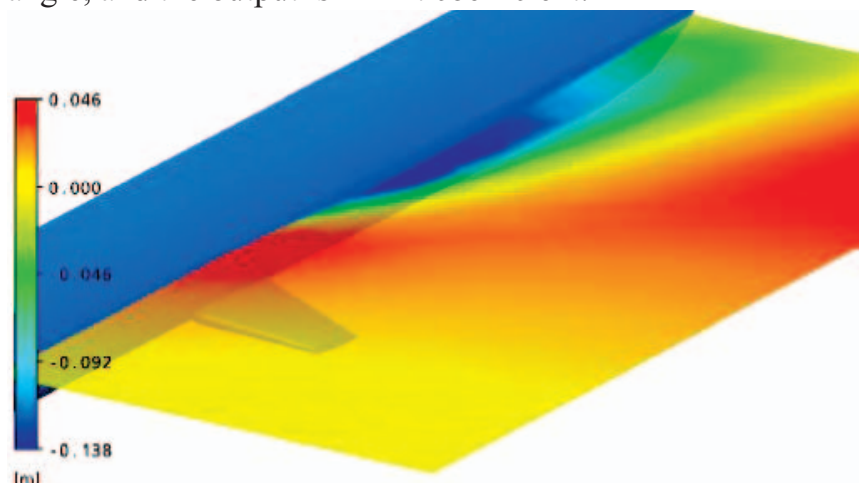

Fig. 2. Free surface profile around ship body and attached fin, at $8 \mathrm{~m} / \mathrm{s}$ forward speed [7]

There are some constraints imposed by the hydraulic machinery such as: the maximum mechanical fin angle and speed of changing the fin angle. As Fig. 1 shows, after the stall angle the fin's lift coefficient falls down. Moreover, the presented $\mathrm{NN}$ model is not valid after stalling, therefore the stall angle is also added to the model as a constraint. Dynamic effects of the mechanical system used for fin angle changing are represented by a simple integration loop. The maximum mechanical fin angle and its maximum rate of change are assumed to be 25 degrees and 25 degrees per second, respectively, i.e. usual design values [8]. Fig. 4 shows the considered model.

To calculate a correct effective angle of attack is also important. As mentioned before, the effective angle of attack refers to the angle between net input velocity of foil and flow.
The net velocity will be here the summation of the inflow velocity due to ship forward speed and that due to ship rolling motion. Therefore another block added to the model to calculate the effective angle of attack is based on Eq. (3). Fig. 5 shows the complete model of the fin. The input to the fin's model is the desired fin angle, and the output is the fin lift coefficient accounting for the mechanical system dynamics and the flat free surface effects. Next, the fin's roll moment is calculated by multiplying the lift coefficient and a calibrating gain calculated from Eq. (4).

According to the results presented in Fig. 3, because of the free surface effects, two identical fins placed on two sides of the ship do not give the same roll moment even at equal angles of attack. Therefore to better model the fin stabilizer two fin models shown in Fig. 5, are used.

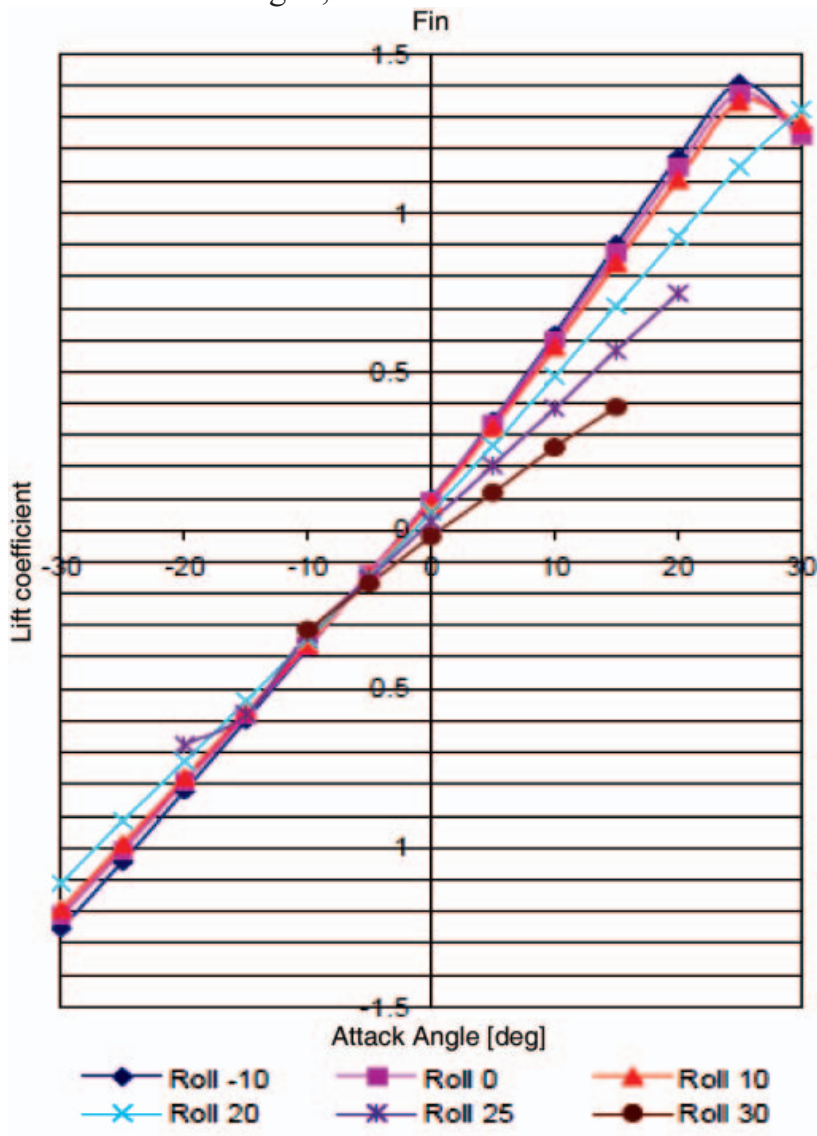

Fig. 3. Lift coefficient in function of angle of attack and various ship roll angles, $U=8 \mathrm{~m} / \mathrm{s}[7]$

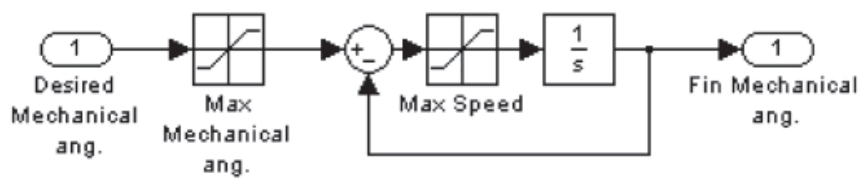

Fig. 4. Block diagram of fin mechanical system
Fin

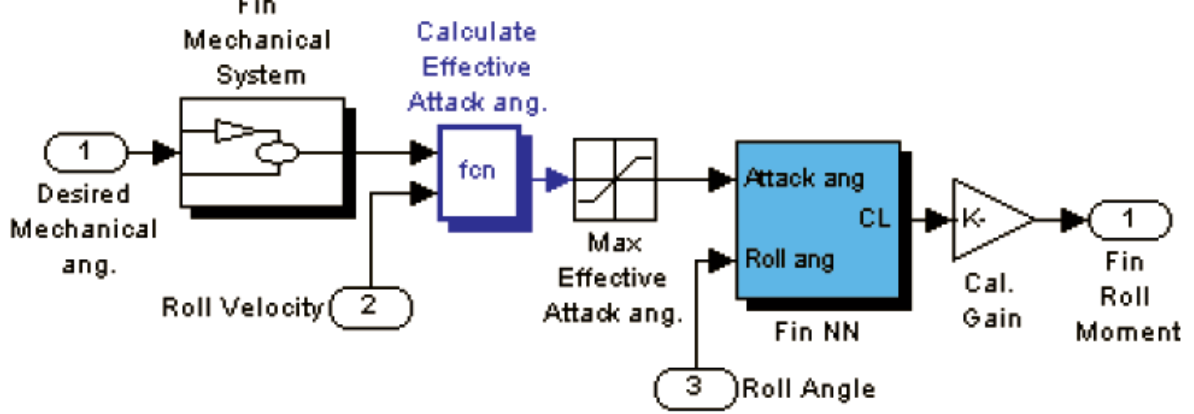

Fig. 5. Block diagram of fin model combined with mechanical system 


\section{CONTROL LOOP AND RESULTS}

The next step is forming the controlling loop. To accomplish this and overcome complexities of models different controlling methods such as PID and neural network are combined. The PID controller is used as a main controlling tool. For considering complex behaviour of roll moment in function of roll angle in case of large angles and forward speed, an inverse neural network model is trained by using the Error Back Propagation technique (EBP) based on the results achieved from the introduced ship dynamic model. The input for the trained NN model is the heel angle and the output is the heeling moment caused by the input heel angle.

At the first step a simple controlling loop shown in Fig. 6 , is used. The NN model of the ship heeling moment is placed in a closed control loop. Then the NN gains are optimized against positive and negative external pulses as disturbances, by using a genetic algorithm. By doing so, a more accurate and stable NN model for heeling moment is achieved.

In the next step the PID controller was added to the NN as shown in Fig. 7. Then the PID gains were optimized by using the genetic algorithm to achieve optimized controlling performance in response to the same disturbances as before. The gains were used as the first estimation for the complete controlling loop containing fin models.
The heel moment resulting from the NN model was considered as the desired roll moment which should be interacted by the fin stabilizer. The desired roll moment should be divided in two portions, translated into desired mechanical fin angle and then passed to the fin model. To achieve this, an inverse $\mathrm{NN}$ model of fin lift coefficient, was trained. Equal moments acting on two fins were used, which was equivalent to equal portions of heeling moment. Other portions could be also used to achieve equal angles of attack or maximum efficiency of fin stabilizer. The arrangement for one fin is shown in Fig. 8.

The output of the fin model will be an actual restoring moment produced by the fin stabilizer. In this step for this new arrangement the genetic algorithm is used to optimize PID gains against the same pulse disturbances. Therefore the steps of the complete controlling loop shown in Fig. 9, could be summarized as follows:

1. the PID controller receives vessel's roll angle and generates a suitable command;

2. the PID command is translated to a desired total restoring moment;

3. the desired total restoring moment is divided in two equal portions, one for each fin;

4. the desired moment for each fin is translated into a lift coefficient by dividing it by a calibrating gain;

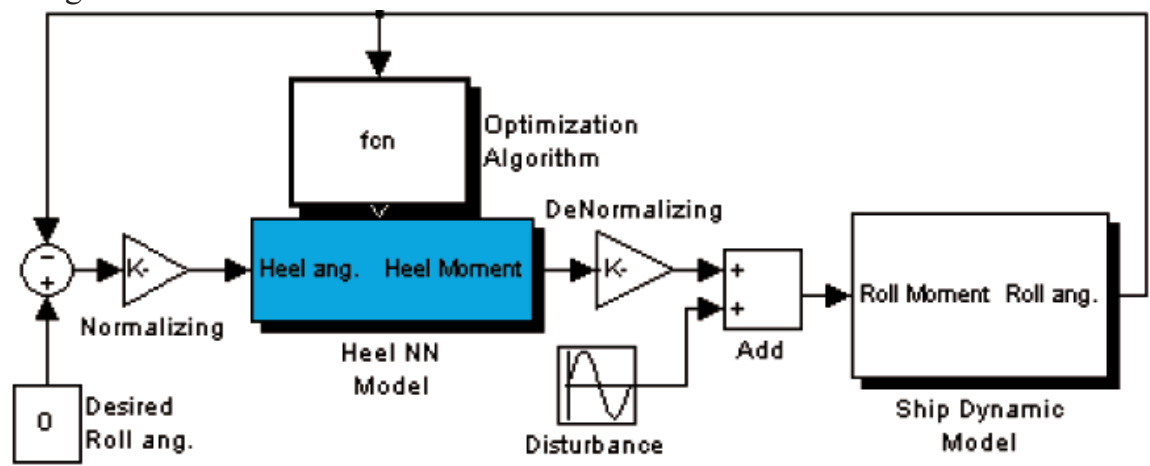

Fig. 6. Optimizing the NN gains in controlling the heel moment without application of fins, performed by means of a genetic algorithm

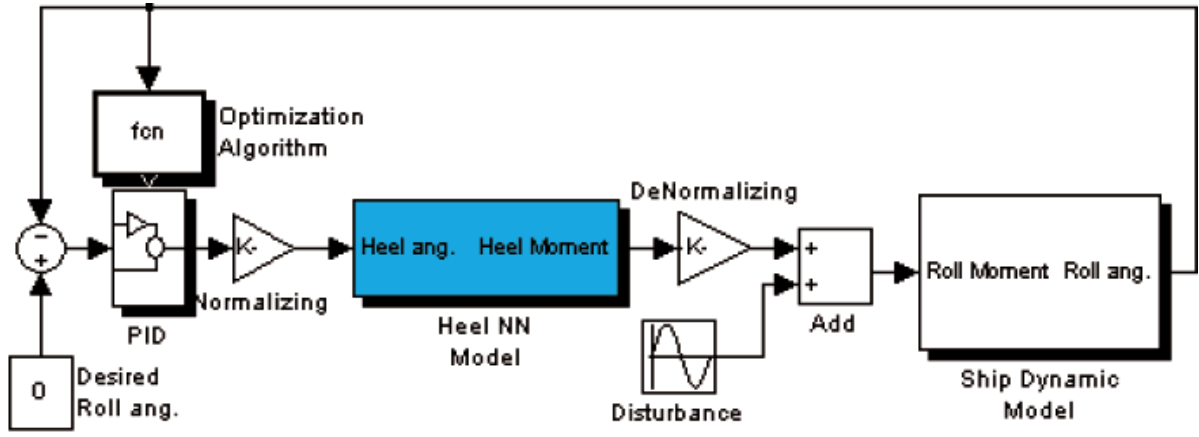

Fig. 7. Optimizing the PID gains in controlling roll moment of the vessel without fins, by using genetic algorithm

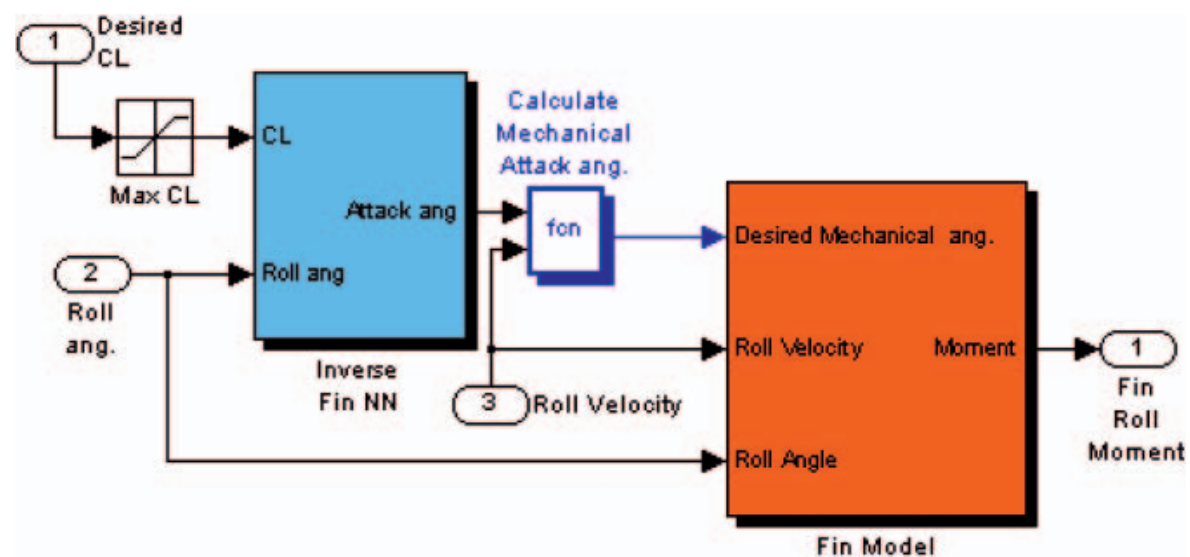

Fig. 8. The arrangement for translating the desired CL into the desired mechanical angle and actual fin moment 


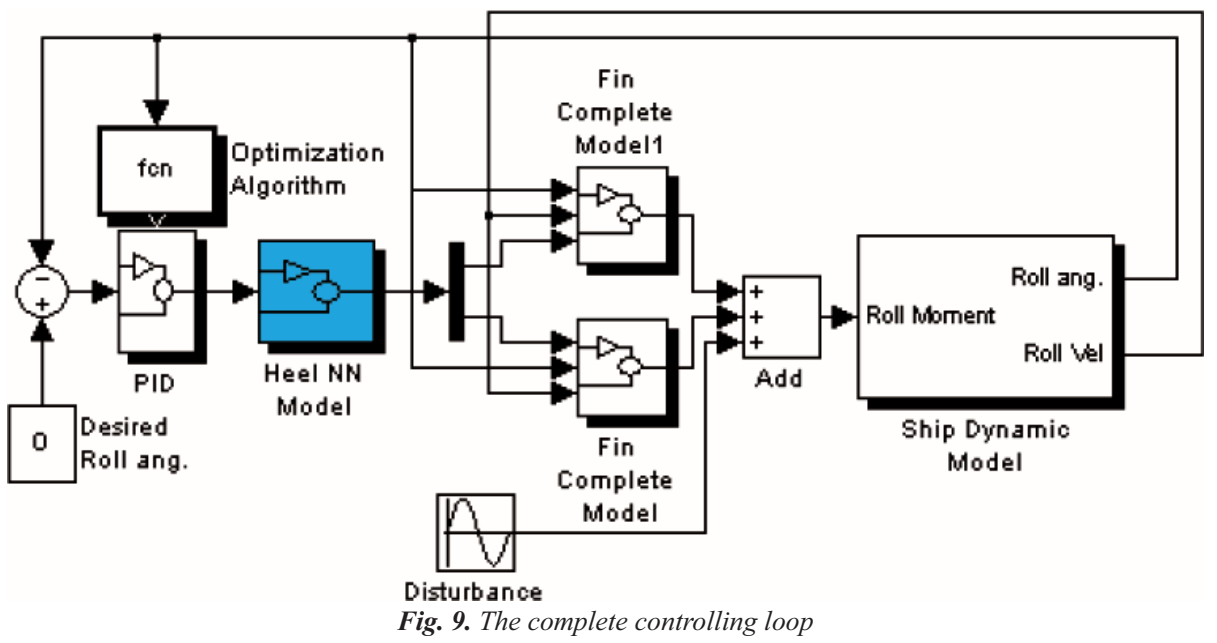

5. each resulted lift coefficient is checked and constrained by the maximum fin lift coefficient;

6. the lift coefficient is translated into a fin effective angle of attack by using the inverse NN model of fin lift coefficients;

7. by considering ship roll velocity, a desired mechanical attack angle is calculated and passed to the fin model;

8. the fin model gives an actual fin restoring moment by accounting for a fin mechanical system delay and free surface effect;

9. the fins' restoring moments are added to the environmental roll exciting moments and passed to the ship's dynamic model;

10. the ship dynamic model gives a new roll angle and roll velocity to be used in the next step.

The model responses to two roll exciting moments are simulated. Fig. 10 shows two sample time history of the exciting

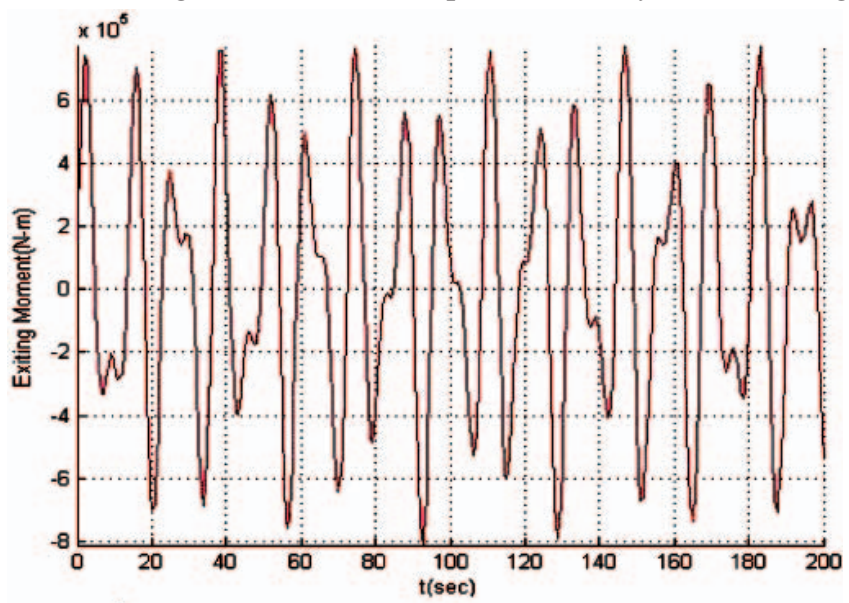

moments. The upper figure is considered the case (a) and the lower figure - the case (b).

Fig. 11 shows ship's roll angle time history in case of the forward speed of $8 \mathrm{~m} / \mathrm{s}$ in presence of the exciting roll moment (a), with and without fin stabilizers. As showed, the ship roll angle is reduced by using the active fin models. It is important to note that the fin angles are not necessarily the same on both sides of the ship and each fin angle is optimized by considering the free surface effects. Fig. 12 shows the same results for the case (b). Although the complex model including the free surface effects was used for fin stabilizers, the designed controller was capable to reduce roll angle amplitude effectively.
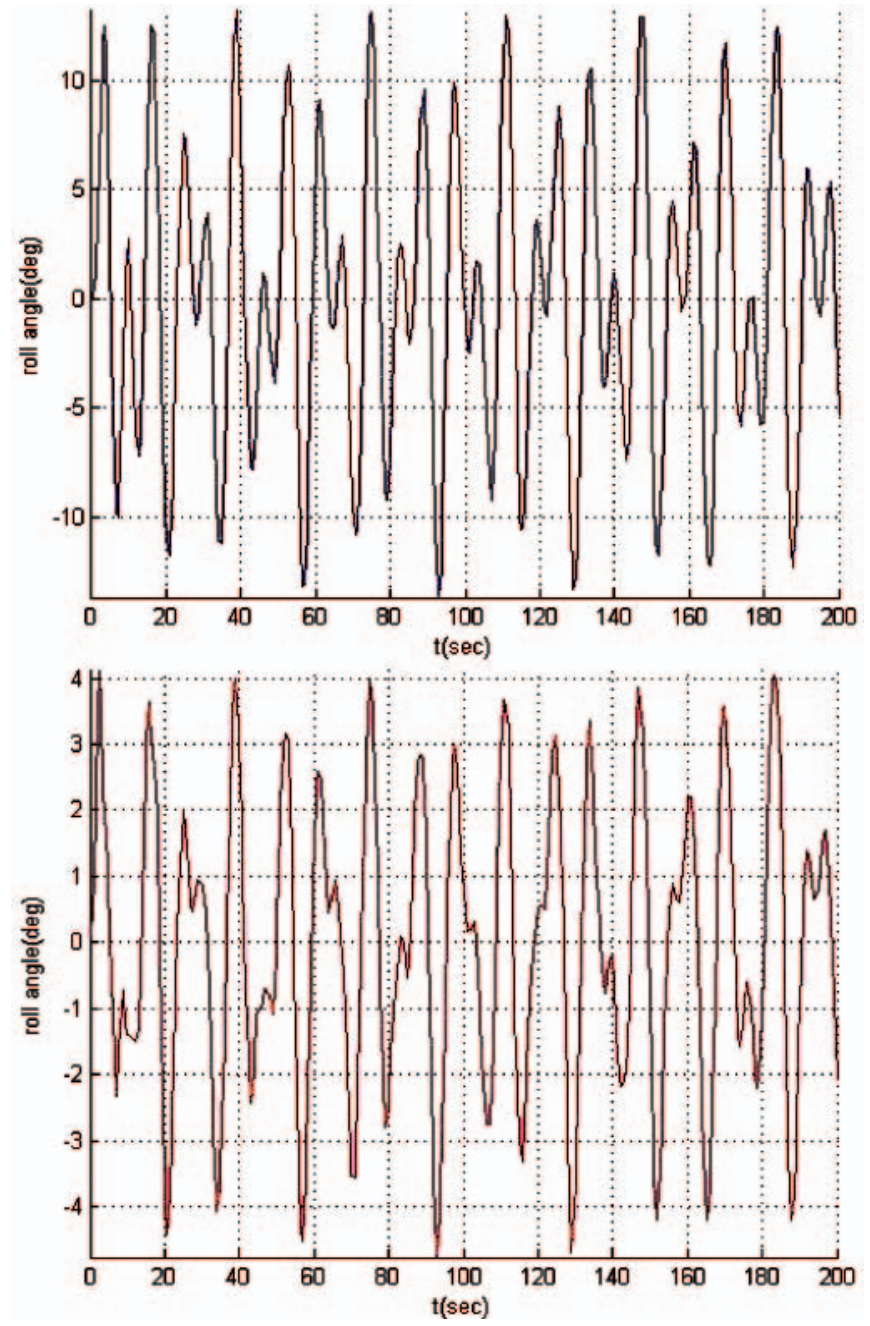

Fig. 11. Time history of roll angles for the exciting moment (a): the upper figure - without action of the controller, the lower figure - with action of the controller 

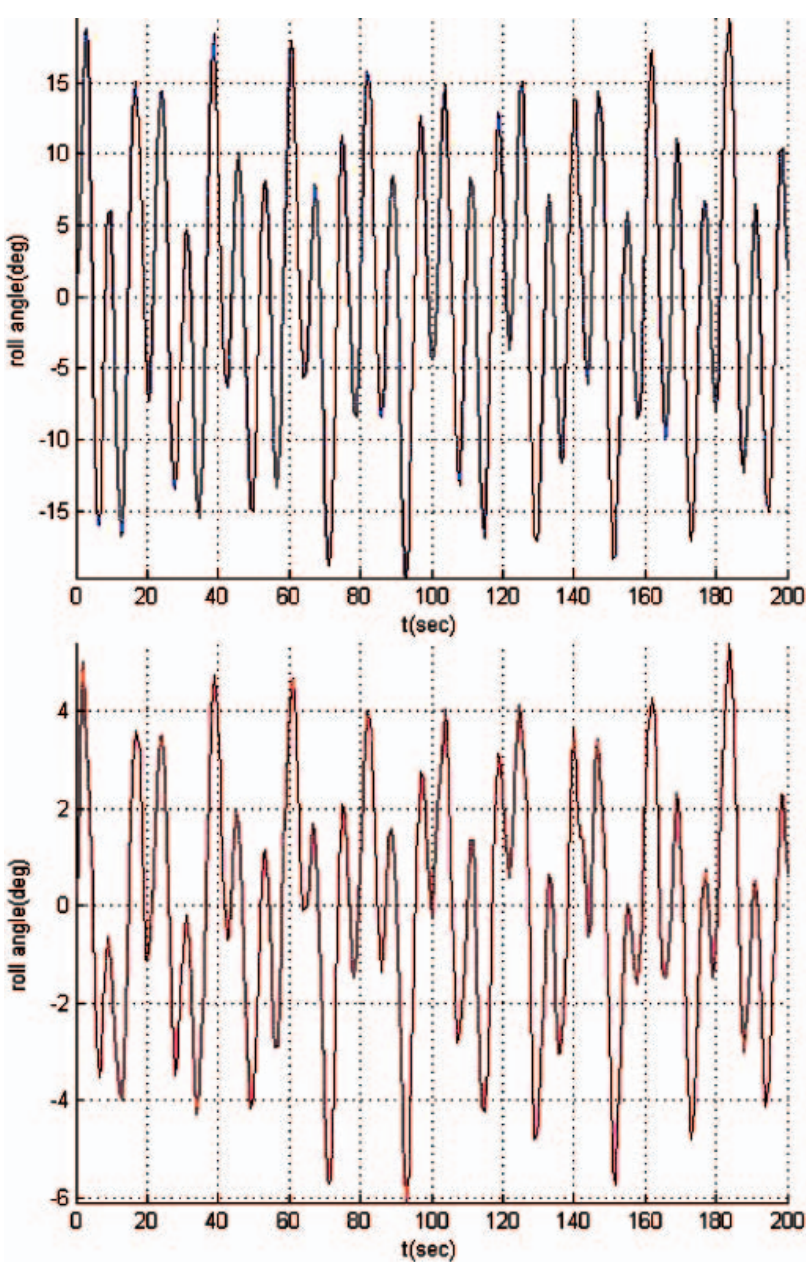

Fig. 12. Time history of roll angles for the exciting moment (b): the upper figure - without action of the controller, the lower figure - with action of the controller

\section{CONCLUSION}

New fin models accounting for free surface effects were developed to be used in dynamic modelling of ships with fin stabilizers. By using the new model the fin stabilizer dynamic model was improved. A neural network model was trained on the basis of CFD simulation of hydrodynamic behaviour of a fin close to free surface.

For the effective controlling of fin stabilizers combined PID - NN controllers were used. Two fins placed on both sides of the vessel were controlled in a different way to overcome unsymmetrical behaviour resulting from free surface effects. By doing so, more realistic and efficient behaviour of fins were achieved.

A genetic algorithm was used to optimize behaviour of NN and PID controlling system. Good performance and response of the controlling system was achieved by using the controlling approach even to more complex fin models.

\section{NOMENCLATURE}

$\phi \quad-\quad$ Roll angle

$\phi \quad$ - Roll velocity

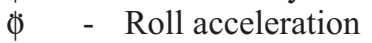

U - Ship service speed

h - Immersed depth

$\mathrm{Fn}_{\mathrm{b}}$ - Submergence Froude number

$\mathrm{C}_{\mathrm{L}}$ - Lift coefficient

$r_{f}-$ Fin arm

$\mathrm{C}_{\mathrm{p}}-$ Pressure coefficient

$\alpha$ - Fin attack angle

$\alpha_{\text {eff }}$ - Effective attack angle
L - Ship Length.

B - Ship Breath

D - Ship Draft

$\Delta \quad$ - Ship Displacement

$I_{z z} \quad$ - Ship Moment of Inertia around $\mathrm{Z}$ axes

$I_{x x}^{z z}$ - Ship Moment of Inertia around X axes

KM - Ship meta-centric height from keel

KB - Ship center of buoyancy from keel

GM - Distance between ship's center of gravity and metacenter

LCG - Ship's longitudinal center of gravity

VCG- Ship's vertical center of gravity

PID - proportional-integral-derivative controller

NN - Neural Network

CFD - Computer Fluid Dynamics.

\section{BIBLIOGRAPHY}

1. Whicker L.F., Fehlner L.F.: Free-stream characteristics of a family of low aspect-ratio, all-moveable control surface for application to ship design. DTMB report, 1958

2. Pitt W.C., Nielsen J.N., Kaatari G.E.: Lift and center pressure of wing-body-tail combinations at subsonic, transonic and supersonic speeds. NACA report 1307, 1959

3. Sheldahl R. E. and Klimas P. C.: Aerodynamic, Hydrofoil data, Sandia National Laboratories, Albuquerque, New Mexico, March 1981

4. Newman J.N.: Marine Hydrodynamics, 1977

5. Bal S., Kinnas S. A., Lee H.: Numerical analysis of 2-D and 3-D cavitating hydrofoils under a free surface, J. Ship Res., 45, 1, 2001

6. Lee C.M., Park I.R., Chun H.H., Lee S.J.: Effect of free surface and strut on fins attached to a strut, Ocean Engineering 28, 2000

7. Hoseini Dadmarzi F., Ghassemi H., Ghadimi P., Ommani B.: Flow field analysis around the ship fin stabilizer including free surface, Proceedings of the OMAE2009, Hawaii, USA, 2009

8. Tristan Perez: Ship motion control: course keeping and roll stabilization using rudder and fins, Springer 2005

9. Surendran S., Lee S.K., Kim S.Y.: Studies on an algorithm to control the roll motion using active fins, Ocean Engineering 34, 2007

10.Lian Yan-hua, Jin Hong-zhang, Liang Li-hua: Fuzzy-PID controlled lift feedback fin stabilizer, J. Marine. Sci. Appl. (2008) 7

11.Wu C. and Huang C.: A Neural Network Controller with PID Compensation for Trajectory Tracking of Robotic Manipulators, J. Franklin Inst. Vol. 333(B), No. 4, 1996

12.Zirilli A., Roberts GN., Tiano A., Sutton R.: Adaptive steering of a containership based on neural networks, International Journal of Adaptive Control and Signal Proceedings of the Int. J. Adapt. Control Signal Process. 2000; 14

13.Alarcin F., Gulezb K.: Rudder roll stabilization for fishing vessel using neural network approach, Ocean Engineering 34, 2007

14.Blanke M. and Christensen A.: Rudder-roll damping autopilot robustness to sway-yaw-roll couplings. $10^{\text {th }}$ Ship Control Systems Symposium, Ottawa, Canada (1993).

\section{CONTACT WITH THE AUTHORS}

Hassan Ghassemi, Associate Prof.

Fatemeh Hoseini Dadmarzi, MSc Graduated

Parviz Ghadimi, Assistant Prof.

Faculty of Marine Technology

Amirkabir University of Technology

Hafez Ave.,

Tehran, IRAN

e-mail: gasemi@cic.aut.ac.ir

Babak Ommani, MSc Graduated

Faculty of Mechanical Engineering, Sharif University of Technology, Tehran, IRAN 